\title{
Digital Equality and the Uptake of Digital Applications among Seniors of Different Age
}

\author{
Annika Bergström
}

\begin{abstract}
Ageing societies are facing challenges from the perspective of the use of information and communication technologies (ICTs). There is an increase in online services relevant for the economic, political, cultural and private life. Those who participate more fully in a digitally mediated social life enjoy advantages over their digitally disadvantaged counterparts. Today's digital divide is not first and foremost between pensioners and others, but between younger and older pensioners. Scholars identify the need for longitudinal research among younger and older seniors to understand the differences between more or less advantaged users. Based on longitudinal, representative surveys, the present study finds that there is a clear gap between younger and older seniors, and that it is closing only very slowly. Age and level of education are powerful explanatory factors whereas generational belonging and social capital contribute only to a limited extent to the understanding of Internet uptake among older adults.
\end{abstract}

Keywords: Internet use, senior citizens, usage gap, digital divide, longitudinal surveys

\section{Introduction}

Ageing Western societies are facing challenges from the perspective of the use of information and communication technologies (ICTs) to enhance quality of life by sustaining independent living and providing opportunities for greater democratic and societal engagement (Boulton-Lewis et al. 2007, Loos 2012, Obi et al. 2013, Rains 2008). Personal computers and the Internet are seen as increased opportunities for communication, information and entertainment, and with regard to the services that can be accessed (Carpenter \& Buday 2007, Dickinson \& Gregor 2006, van Deursen \& Helsper 2015). Those who function better in the digital realm and participate more fully in a digitally mediated social life enjoy advantages over their digitally disadvantaged counterparts (Robinson et al. 2015).

Internet activities such as financial matters, entertainment, shopping, information and news offer opportunities that could be beneficial particularly for seniors limited in mobility (Reisenwitz et al. 2007). Using a home computer would enable older people to continue living independently in their own homes, and communication technologies are said to have the potential to minimise social isolation (Boulton-Lewis et al. 2007, 
van Deursen \& Helsper 2015). Further, the Internet is recognised as a valuable tool for acquiring information in general, and specifically health information (Rains 2008).

For many older people, dealing with everyday problems does not involve the personal use of ICT. The combination of this increase in online services and the disparity in their use leads to inequalities at the level of individuals, social groups and nations (Friemel 2016). Today's digital divide is not first and foremost between pensioners and others, but between younger and older pensioners. Among older adults, Internet use is strongly skewed leading to a partial exclusion for the old seniors (ibid).

Research on seniors' uptake of the Internet and related applications has been studied in several areas and from different perspectives. There are, however, some limitations and gaps. The majority of scientific research applies an upper age limit and there is relatively limited knowledge of the digital divide among seniors above the age of 65 years (Dickinson et al. 2007, Friemel 2016). Further, older adults are often considered a homogenous group, practising a uniform range of activities. Research needs to examine more closely how different older adults interact differently with the Internet (van Deursen \& Helsper 2015). The usage gap hypothesis claims that Internet use reflects differential uses and activities in all spheres of daily life meaning that off-liners could be excluded from both benefits and pleasure. Many studies do not take into account any subsequent divides following use of more specific applications and the uptake of certain areas of use in the wide variety of supplies on the Internet (Friemel 2016).

In order to understand the ongoing development, how it takes place in a social context, and also what will happen in the future, accumulated knowledge from activities and habits in the past are crucial (Bouwman \& Van Der Duin 2007, Brügger 2013). When trying to predict digital exclusion in society, it is also important to have an understanding of diffusion patterns based on generalisable data on large populations in the longer term (Robinson et al. 2015).

The aim of the present analysis is to study the uptake of Internet and specific areas of use in different age groups and cohorts of older adults in Sweden. Longitudinal, crosssectional survey data of representative samples up to the age of 85 years allow analysis of the impact of background factors of different kinds. The data set contains both general Internet use and several specific areas, making it possible to study in-depth usage gaps. Sweden is a country with high levels of general Internet diffusion and provides a case study for understanding what the future situation will be with regard to older adults' uptake of different ICT related applications.

\section{Theoretical perspectives}

Digital inequality can be defined from the perspectives of access, usage, skills and self-perceptions (Robinson et al. 2015). This study focuses on usage and will have its point of departure in theories explaining who takes up use of new media technologies.

The process of diffusion of innovations takes place in a larger social context, where social factors, or 'supervening social necessities' (Winston 1998) are operating. Winston argues that social needs are more significant than specific features of the innovation or of the habits to use it. Diffusion of media technology is sometimes described in terms of technology determinism and fails to include a wider perspective of trends and social change (Bouwman \& Van Der Duin 2007, Winston 1998). 
The diffusion process of media, not least Internet adoption, most often follow familiar patterns identified both empirically and theoretically. The so-called diffusion of innovations theory (Rogers 2003) is commonly used. Rogers discusses that technological adoption is predicted by perceived attributes of innovations (relative advantage, compatibility, complexity, observability and trialability), social norms, and individual characteristics. Another perspective related to this is suggested by Davis (1989) in the technology acceptance model (TAM). Davis emphasises both factors of innovation, such as perceived usefulness and perceived ease of use, and contextual factors as important determinants of uptake of technical innovations. The specific factors identified by Davis are closely related to Roger's concept of 'relative advantage' and 'complexity', and Davis notes that users might be willing to cope with some difficulties if the innovation provides a desirable functionality.

The TAM model introduces social norms as a factor of direct impact on how perceived usefulness is interpreted. It is of importance whether and how individuals feel the pressure from others to use new media technology. This experience influences perceived usefulness and might have a persuasive effect (Verkasalo et al. 2010).

Some groups in a society are always more eager than others to learn new techniques. These so-called innovators actively seek the new, which is often associated with fashion and trend-setting and the innovators are therefore mostly young (Rogers 2003). The next group is, according to this categorisation, the early adopters. Since new technologies often are relatively expensive and also demand a certain amount of knowledge, the early adopters usually are well-educated and relatively wealthy. Then follows early and late majority, where most of the population have adopted the innovation. Last there are the so-called laggards who might never take up the innovation. This group is characterised by high age, lower level of education and being traditionalists. The diffusion patterns are well-known in the context of the last decade's digital media development.

The diffusion of media technology and use of it has proven to be strongly related to socio-demographic factors. Age particularly plays an important role for the adoption of digital technology, and younger persons are over-represented among the so-called innovators and early adopters (Rogers 2003). When studying formal, operational Internet skills, it is also evident that older people perform more poorly than younger ones, and on a general level, younger persons are overrepresented in generating and uploading content in digital contexts like Wikipedia, social communities and discussion forums (Davis 2005, Fisch \& Gscheidle 2008, Lenhart et al. 2007). The digital divide is not only evident between younger and older generations, but above all within the senior group, where the older seniors to a large extent are excluded (Friemel 2016).

Age alone might not be the only effect related to time. Differences in Internet usage might well appear differently in different cohorts. Common for a cohort is, according to Mannheim (1952), common references to influences of historical time that are specific for a group of people born within a specific time (birth cohort), bringing them to a perceived common core of experiences. People are formed by the period in which they grew up and by the broader social groupings they were surrounded by. Altogether, according to Mannheim, a generation shares temporal, historical and sociocultural locations. There is evidence that different technology generations behave differently due to differences in technology experience during their formative years (c.f. Docampo Rama et al. 2001). A lack of Internet experience during an earlier period of life has proven to 
be one of the reasons why some senior citizens do not take up new technology (Loos 2012). One has to consider whether the observation is due to age or cohort (Victor et al. 2007). Among people who are found within the group of pensioners today, no one has grown up with the Internet, and among the oldest people, it is reasonable to assume that computer experience in general is limited.

Previous research has found sex differences both for Internet use and motives for taking up the technology. Early studies on computer and Internet use found computer culture to be perceived as male in terms of content, structure and availability (Gersch 1998, Turkle 1995). More specific Internet studies also found considerable differences between men's and women's combinations of areas of use and interest in different content and devices (Fisch \& Gscheidle 2008, Hargittai 2008, Hargittai \& Malejko 2008; see Helsper 2010 for an overview). When focusing on older adults, research is, however, somewhat inconsistent with regard to sex differences in Internet use. Van Deursen \& Helsper (2015) find that among older adults, Internet use is a male-dominated activity. When online, they conclude, men engage more in individual recreational activities, whereas women turn to more social activities. In a study from Friemel (2016), however, sex becomes insignificant when controlled for age, education and income.

Socio-economic indicators, particularly formal education, have also proven to affect the willingness to take up new media technologies like the Internet. According to Rogers (2003), people with higher formal education are more likely to be early adopters of technological innovations. Education is also an important factor significantly affecting perceived usefulness of the Internet (Reisenwitz et al. 2007). According to Friemel (2016), education has a strong and separate influence on the Internet use of seniors. Van Deursen and Helsper conclude that highly educated senior Internet users are more involved in 'knowledge enhancing activities of information and news' (Van Deursen \& Helsper 2015:183).

As highlighted by Davis (1989) and Winston (1998), media use needs to be put in a larger social context. Also more recent research emphasises the fact that media is an integral part in several aspects of social life, and consequently needs to be studied within a larger framework. There are studies proving that adoption of new media technologies is more common among people exposed to such in their close surroundings (Haddon 2000), and that people tend to learn faster when included in social networks. Helping and supporting each other also leads to higher Internet skills (van Deursen \& van Dijk 2011). Social capital has proven to be of great importance for Internet uptake among seniors; support and encouragement by social network members is crucial (Friemel 2016). Older people start to use a computer and the Internet when encouraged by family members (Gatto \& Tak 2008), whereas older adults living alone have been shown to be less likely to use the Internet since they do not learn from partners or someone else in the household (van Deursen \& Helsper 2015).

Putting adoption research in a wider context also means including contexts outside home. It has been shown that workplaces have played an important role for adoption of new technologies as many people first get in contact with information and communication technologies in work settings (Haddon 2006). To many people, workplace situations are where they have learnt how to use computer based technologies and also in what ways they can be useful (Haddon 2000). Among older adults, there is a strong influence of pre-retirement computer use (Friemel 2016). Users may take advantage of 
earlier acquired knowledge when using the Internet, and a knowledge base from, for instance, previous work might make it easier to encode and integrate new information (Docampo Rama et al. 2001). Younger older adults are bringing computer skills learned from work and hobbies into their retirement (Gatto \& Tak 2008).

It is evident from the theoretical outline that the uptake of new media technology such as the Internet and related applications is a complex composition of factors related to both individuals and society. Further, digital media are subject to development and continue to evolve. It is therefore probable to assume that different factors have different influences at different times, and that the patterns will repeat themselves with new applications. The aim of this article is to reveal how groups of older adults have adopted the Internet and the techniques and applications related to it over a couple of decades, and the factors that have affected the uptake at different times. The findings will contribute to the understanding of the process of digital applications diffusion among the elderly.

The analysis is based on two research questions:

- How does the uptake of the Internet evolve in different age groups among senior citizens?

- How important is age for the diffusion process among the elderly in relation to other factors?

The survey is conducted in Sweden, which is one of the highest ranking countries when comparing Internet access, skills and usage (Internet World Stats). The preconditions for using the Internet and Internet related applications are favourable, and the data will give insight in diffusion and uptake of digital facilities when pre-requisites are very good.

\section{Method}

The uptake of the Internet and digital applications among specific groups of older adults was captured in a longitudinal survey with a representative sample of the Swedish population. The study is based on data collected in the Swedish national Society, Opinion, Media (SOM) surveys conducted as an annual mail survey since 1986. Each year between 3,000 and 17,000 persons aged 16 to 85 and living in Sweden have received the SOM survey. The surveys from 1998 to 2015 are included in the analysis. Although questions on Internet use were posed as early as 1995, the decision was made to include data from when there was 20 per cent diffusion with reference to Docampo Rama et al. (2001), suggesting this is a relevant beginning for a period in longterm diffusion studies. Use of specific Internet applications was measured for the first time in 2005.

The survey design has altered somewhat across the years. In 1998 and 1999, the sample was 5,600 persons aged 15 to 80 years. From 2000 to 2008, the sample was 6,000 persons aged 15 to 85 years. In 2009 to $2011,9,000$ persons aged 16 to 85 years were included in the sample, which was expanded to 12,000 persons in the 2012 and 2013 surveys, to 13,600 in 2014 and to 17,000 in the 2015 survey (see Vernersdotter 2016 for details on research design).

The average net response for the whole period is 63 per cent. The highest response rate was found in the 1996 and 1997 surveys (69 per cent) and the lowest in 2015 (51 per cent). The respondents are divided in almost the same way as the Swedish population in terms of gender, social class and level of education. Older people are, however, 
over-represented since the response rate in the youngest groups is below average. As with other statistical surveys, this one gives a general picture of the development of Internet use and use of Internet related applications. The methodological choices, however, cannot give more in-depth information about why Internet use is taken up by people.

The average questionnaire consists of approximately 16 to 20 pages and 70 to 90 questions, most of them with fixed answer options. There are several editions with a somewhat different focus. Questions on the dependent variables analysed in this study - Internet use and specific areas of use - were posed 'How often during the last 12 months have you used the Internet/How often do you usually use the Internet to do the following?' Between 1995 and 2007 a seven-point scale was used: Never, Once during the last 12 months, Once during the last 6 months, Sometime in the last three months, Once a month, Once a week and Several times a week. In the 2008 survey, the option Daily was added. To obtain comparable data across the period, Several times a week and Daily are merged in the dataset. The question on general Internet use was posed in all questionnaire editions in the survey. The number of editions has, however, varied over the years, which is why the number of respondents also varies. Questions on specific areas of use are posed in one or more questionnaires over the years, and the number of respondents also varies in this sense.

The independent variables are captured in several different survey questions. Sociodemographics such as sex and age (year of birth) are integrated with the dataset from public registers. The birth cohorts are constructed as follows: born in 1910-1919, 19201929, 1930-1939 etc. Socio-economic status is measured by educational level. Education was measured in eight categories, then divided into three groups: low, medium and high educational levels. Previous employment status was measured in five categories: have never worked (1), blue-collar worker (2), self-employed without employees (3), self-employed with employees (4), white-collar worker (5). Social capital is measured by variables of household composition and frequency of socialising with friends. The former question regards if you live alone (1) or if you share household with other adults or children (2). The latter question was posed: How often during the last 12 months have you hung out with friends? A seven-grade scale was used: Never (1), Once during the last 12 months, Once during the last 6 months, Sometime in the quarter, Once a month, Once a week, Several times a week (7).

\section{Findings}

The analysis of general Internet use and use of specific online applications among older adults is made in two steps. First, a bivariate analysis over the years is conducted, then follows a multivariate regression analysis for some selected years to reveal the single contribution of age when taking socio-demographic and other variables into consideration.

On a general level, the uptake of the Internet has been relatively slow among the older part of the population in comparison to the population average (Table 1). There are, however, large differences when comparing different groups of elderly and the development over the years varies widely due to age. Already in the mid-2000s, the youngest group of elderly (60 to 64 years) were on roughly the same level as the average population. The diffusion took a relatively long time among seniors aged 65 and above, 
and the uptake among people aged $80+$ has only recently started. While about 80 per cent of the younger seniors are frequent Internet users (daily or several times a week), the level is about one third among the oldest.

The findings support what is outlined in theories on technology diffusion and acceptance (Davis 1989, Rogers 2003) and inequalities within the group of elderly citizens identified in previous research (c.f. Friemel 2016).

Over the years, many social attempts have been made to encourage older people to gain access to and to take up digital applications. The development and the present state show that these attempts might have been only partly successful, and that uptake of digital technology is part of a complex process not only including mere access.

Table 1. General use of the Internet in age groups and national average (per cent several times a week)

\begin{tabular}{|c|c|c|c|c|c|c|c|c|c|c|c|c|c|c|c|c|c|c|}
\hline & 1998 & 1999 & 2000 & 2001 & 2002 & 2003 & 2004 & 2005 & 2006 & 2007 & 2008 & 2009 & 2010 & 2011 & 2012 & 2013 & 2014 & 2015 \\
\hline $60-64$ years & 8 & 17 & 16 & 28 & 31 & 31 & 40 & 48 & 49 & 56 & 59 & 65 & 70 & 71 & 81 & 84 & 79 & 84 \\
\hline $65-69$ years & 6 & 0 & 14 & 14 & 13 & 20 & 29 & 32 & 26 & 45 & 53 & 56 & 65 & 70 & 74 & 72 & 69 & 78 \\
\hline $70-74$ years & 0 & 4 & 2 & 14 & 9 & 10 & 14 & 22 & 23 & 23 & 22 & 42 & 49 & 46 & 54 & 69 & 67 & 73 \\
\hline $75-79$ years & 0 & 3 & 3 & 3 & 13 & 8 & 11 & 3 & 8 & 8 & 20 & 31 & 40 & 48 & 50 & 51 & 46 & 53 \\
\hline $80-85$ years & 0 & 4 & 3 & 3 & 4 & 9 & 11 & 4 & 9 & 4 & 8 & 19 & 11 & 23 & 15 & 24 & 25 & 33 \\
\hline $\begin{array}{l}\text { Average, } \\
16-85 \text { years }\end{array}$ & 22 & 29 & 36 & 40 & 41 & 48 & 51 & 51 & 57 & 60 & 65 & 72 & 73 & 74 & 77 & 80 & 79 & 82 \\
\hline$n=$ & 196 & 199 & 211 & 214 & 201 & 215 & 226 & 213 & 222 & 240 & 237 & 360 & 369 & 360 & 513 & 518 & 580 & 686 \\
\hline
\end{tabular}

Comment: Average 16-85 years is calculated on un-weighted data.

The picture drawn above clearly shows differences among different groups of elderly people, and it is likely to assume, just as outlined in the theoretical section, that driving forces might differ and also might play different roles for the uptake at different times. A multivariate analysis including socio-demographic factors, previous work position and social factors shows a relatively high explanatory power of the total model, especially since 2005 (Table 2; adjusted $\mathrm{R}^{2}$ between 0.33 and 0.28 ). Given that Internet uptake is a moving target, one could assume effects of different explanatory factors to weaken over the years. This is proven in the analysed data.

Table 2. Linear regression analyses (60 to 85 years old), 2000, 2005, 2010 and 2015 (standardised Beta)

\begin{tabular}{|c|c|c|c|c|}
\hline & 2000 & 2005 & 2010 & 2015 \\
\hline Sex $($ female $=1$, male $=2)$ & $0.18^{* \star *}$ & $0.11^{* * *}$ & 0.06 ** & 0.04 * \\
\hline Age (60-85) & $-0.43^{* * *}$ & $-0.25^{* * *}$ & $-0.38^{* * *}$ & $-0.31^{* * *}$ \\
\hline Birth cohort & $-0.21 * *$ & $0.15^{\star *}$ & -0.05 & 0.02 \\
\hline Education & $0.30^{* * *}$ & $0.33^{* * *}$ & $0.36^{* * *}$ & $0.18^{* * *}$ \\
\hline Work position & $-0.07^{*}$ & -0.05 & -0.03 & $0.20^{* * *}$ \\
\hline Household composition & 0.04 & 0.06 * & $0.10^{* * *}$ & $0.13^{* * *}$ \\
\hline Social habits & -0.02 & -0.01 & 0.02 & $0.06^{* \star *}$ \\
\hline Adjusted R2 & 0.21 & 0.33 & 0.31 & 0.28 \\
\hline
\end{tabular}

$* * * \mathrm{p}<0.001, * * \mathrm{p}<0.01,{ }^{*} \mathrm{p}<0.05$ 
The effect of age remains when controlling for several other factors, generational belonging included. In fact, the significantly most important factor explaining Internet use in a multivariate model is age. Its impact varies somewhat over the years, but it is evident that the older seniors use the Internet the least. The effects of birth cohorts were rather high in the 2000 survey, and have weakened over the years. The development indicates that, over the time period studied, more cohorts have experienced digital technologies earlier in life, easing use as senior citizens, just as suggested by Loos (2012).

Another factor of independent, significant importance is level of education. The higher the level, the more likely one is to be a more frequent Internet user. These findings are in line with general diffusion theory (Rogers 2003) and also with recent findings more specifically focusing on different aspects of Internet use (Friemel 2016, Reisenwitz et al. 2007, van Deursen \& Helsper 2015). Work position, however, has little or no single significant effect in 2000, 2005 and 2010, whereas the explanatory power is high in 2015, when larger groups of seniors could be assumed to have computer experience from previous work.

The impact of sex was significantly higher in 2000 than 15 years later. Although differences between men's and women's use of the Internet have diminished, it is evident that the uptake and continuous use is more of a male activity than a female one. Sex differences among older adults found in this study, support previous single measurements by showing significantly higher use among men in earlier research (c.f. Helsper 2010) and insignificant effects of sex in more recent studies (Friemel 2016).

It seems that household composition and social habits have little or no significant impact on the uptake of the Internet among older adults when controlling for other factors. The impact of different social resources found in previous research (Friemel 2016, Gatto \& Tak 2008, van Deursen \& Helsper 2015) is not significant in this study. Over the years, other factors prove to have stronger explanatory power. But as shown in Table 2, household composition and social habits have increased their importance in the 2010s. The study cannot give in-depth insight to why this is, but one part of the change could be the development of social and relational applications like Skype, social network sites and other personal communication features. These could, as mentioned in the theoretical part, be part of social life for the elderly, and they require some kind of social interaction with others to be of any use.

General Internet habits include a wide range of activities and have changed over time with a constantly changing Internet environment. To capture more specific means of Internet use, a few areas were chosen for more in-depth analysis. These are e-mail, news services, information search, online banking and use of social network sites. The choice of areas is made to capture a wide range of engagement with other individuals and with society.

Table 3 shows the uptake of the chosen areas between 2005 and 2015 and in different age groups among senior citizens. All measured areas are more commonly used in 2015 than in the mid-2000s, and this is evident in all age groups.

There are rather large differences between younger and older seniors for e-mail use, news services, information search, online banking and social networking. There are two to four times as many weekly users in the group of 65-69 years old than among the $80+$. The difference is relatively larger for social network sites, and smaller for online banking and use of news services. 
The change is, naturally enough, larger among the older seniors who started on a much lower level in the first measurement in 2005. While for instance one third of the 60-64 year olds used online banking in 2005, none of the $85+$ did. With the exception of e-mail, there was not much online activity at all in this group in 2005, although one third claimed to be regular users (Table 1). These findings might reflect an overall increasing desire to be online, but could also be a result of the fixed survey question not capturing activities engaging the oldest seniors. Given that a wide range of commonly used areas was included in the activities battery, it is, however, likely to assume that there is a certain social desirability bias in the answers on general use.

Table 3. Use of e-mail, online news services, information search, online banking and social media networks in different age groups, 2005-2015 (per cent at least once a week)

\begin{tabular}{|c|c|c|c|c|c|c|c|c|c|c|c|c|}
\hline & Age & 2005 & 2006 & 2007 & 2008 & 2009 & 2010 & 2011 & 2012 & 2013 & 2014 & 2015 \\
\hline \multirow[t]{5}{*}{ E-mail } & $60-64$ & 58 & 48 & 54 & 51 & 61 & 74 & 60 & 77 & 75 & 77 & 71 \\
\hline & $65-69$ & 36 & 38 & 46 & 53 & 60 & 60 & 61 & 69 & 68 & 69 & 72 \\
\hline & $70-74$ & 36 & 27 & 21 & 25 & 43 & 40 & 49 & 56 & 54 & 58 & 71 \\
\hline & $75-79$ & 6 & 8 & 9 & 17 & 24 & 41 & 40 & 22 & 46 & 42 & 50 \\
\hline & $80-85$ & 9 & 9 & 9 & 7 & 20 & 8 & 19 & 13 & 16 & 19 & 25 \\
\hline \multirow[t]{5}{*}{ News services } & $60-64$ & 23 & 37 & 39 & 34 & 50 & 52 & 47 & 58 & 63 & 72 & 63 \\
\hline & $65-69$ & 27 & 21 & 30 & 33 & 38 & 30 & 36 & 50 & 56 & 59 & 61 \\
\hline & $70-74$ & 20 & 17 & 18 & 10 & 24 & 22 & 39 & 34 & 43 & 47 & 62 \\
\hline & $75-79$ & 6 & 8 & 3 & 17 & 12 & 26 & 23 & 20 & 37 & 31 & 44 \\
\hline & $80-85$ & 0 & 0 & 0 & 7 & 13 & 6 & 15 & 3 & 16 & 19 & 29 \\
\hline \multirow[t]{5}{*}{ Information search } & $60-64$ & 54 & 46 & 50 & 46 & 59 & 65 & 66 & 77 & 81 & 77 & 84 \\
\hline & $65-69$ & 32 & 30 & 41 & 48 & 48 & 59 & 60 & 69 & 68 & 76 & 71 \\
\hline & $70-74$ & 39 & 27 & 26 & 22 & 32 & 37 & 44 & 52 & 62 & 62 & 72 \\
\hline & $75-79$ & 3 & 8 & 6 & 17 & 22 & 24 & 38 & 20 & 40 & 41 & 46 \\
\hline & $80-85$ & 4 & 4 & 4 & 14 & 18 & 8 & 19 & 14 & 12 & 23 & 33 \\
\hline \multirow[t]{5}{*}{ Online banking } & $60-64$ & 31 & 17 & 20 & 26 & 31 & 35 & 21 & 46 & 39 & 46 & 34 \\
\hline & $65-69$ & 12 & 10 & 31 & 46 & 30 & 32 & 23 & 40 & 37 & 43 & 37 \\
\hline & $70-74$ & 14 & 18 & 24 & 10 & 12 & 23 & 28 & 27 & 40 & 36 & 40 \\
\hline & $75-79$ & 5 & 6 & 11 & 11 & 0 & 18 & 22 & 7 & 27 & 20 & 25 \\
\hline & $80-85$ & 0 & 9 & 8 & 0 & 7 & 4 & 14 & 10 & 0 & 6 & 15 \\
\hline \multirow[t]{5}{*}{ Social network sites } & $60-64$ & - & - & - & - & 14 & 21 & 20 & 33 & 40 & 46 & 43 \\
\hline & $65-69$ & - & - & - & - & 9 & 18 & 18 & 21 & 30 & 30 & 39 \\
\hline & $70-74$ & - & - & - & - & 3 & 3 & 15 & 10 & 24 & 32 & 39 \\
\hline & $75-79$ & - & - & - & - & 0 & 8 & 11 & 2 & 16 & 19 & 29 \\
\hline & $80-85$ & - & - & - & - & 3 & 0 & 6 & 4 & 5 & 11 & 10 \\
\hline N 60-85= & & 213 & 228 & 242 & 243 & 368 & 379 & 374 & 520 & 532 & 597 & 686 \\
\hline
\end{tabular}

Information search is the most common of the measured Internet activities in all senior age groups, and e-mail attracts almost as many. These are also the most widespread activities in the total population. Social network sites like for instance Facebook and Instagram attract four out of ten seniors aged 60-74 years, about three out of ten in the group of 75-79 years old and one out of ten among the oldest citizens aged 80 and above.

It is evident that the general uptake of the Internet is not only unequal within the senior group of Swedes, but also that the digital divide cuts into several dimensions of use of online services and applications. Older seniors aged $80+$ are to a large extent left out of the digital society. 
As already mentioned, age is not the only explanatory factor for uptake of media technologies. A multivariate analysis for each of the areas above will reveal how different factors affect use when consideration is taken of all of them (Table 4). For e-mail, news services and information search, it turns out that education is the single most important factor explaining use. The explanatory power of age is somewhat weaker, but still relatively high. Birth cohort has no independent effect on the uptake of the applications included in the analysis. Other factors such as sex, work situation or household composition only contribute to the overall explanation of use to a limited extent. It is interesting to note, however, that whereas most studied activities attract men to a larger extent, social network sites are found to be more of a female activity also among elderly people (c.f. Hargittai 2008).

Table 4. Use of e-mail, news services, information search, online banking and social network sites, linear regression analyses, 2015 (standardised Beta)

\begin{tabular}{lccccc}
\hline & E-mail & $\begin{array}{c}\text { News } \\
\text { services }\end{array}$ & $\begin{array}{c}\text { Information } \\
\text { search }\end{array}$ & $\begin{array}{c}\text { Online } \\
\text { banking }\end{array}$ & $\begin{array}{c}\text { Social } \\
\text { network sites }\end{array}$ \\
\hline Sex (female=1, male=2) & $0.05^{* * *}$ & $0.11^{* * *}$ & $0.07^{* * *}$ & $0.12^{* * *}$ & $-0.11^{* * *}$ \\
Age $(60-85)$ & $-0.26^{* * *}$ & $-0.19^{* * *}$ & $-0.30^{* * *}$ & $-0.24^{* * *}$ & $-0.21^{* * *}$ \\
Birth cohort & $0.00^{* * *}$ & $0.06^{* *}$ & $-0.01^{* * *}$ & 0.00 & 0.00 \\
Education & $0.40^{* *}$ & $0.26^{* * *}$ & $0.35^{* * *}$ & $0.27^{* * *}$ & $0.12^{* * *}$ \\
Work position & $-0.04^{*}$ & $-0.05^{* * *}$ & $-0.06^{* * *}$ & $-0.07^{* * *}$ & -0.02 \\
Household composition & $0.08^{* * *}$ & $0.06^{* * *}$ & $0.09^{* * *}$ & $0.07^{* * *}$ & $0.04^{*}$ \\
Social habits & $0.08^{* * *}$ & $0.08^{* * *}$ & $0.11^{* * *}$ & $0.07^{* * *}$ & $0.05^{*}$ \\
Adjusted R2 & 0.22 & 0.19 & $0.29^{*}$ & 0.20 & 0.09 \\
\hline
\end{tabular}

$* * * \mathrm{p}<0.001, * * \mathrm{p}<0.01, * \mathrm{p}<0.05$

Patterns of explanatory factors outlined in theory and in analysis above are evident also when going into more detailed Internet use. Education becomes even more significant when studying specific areas. Different social aspects such as work position and social life also become more important than in the analysis of more general use. It is likely that education captures not only knowledge, but also some sort of computer related work situation in previous work life. Occupational orientation is, however, not captured by the work position variable available in the data set. Future research should go beyond the educational factor to reveal in what way higher education contributes to the understanding of the diffusion of online technology among seniors.

\section{Conclusions and discussion}

The present longitudinal study of the uptake of the Internet and several specific applications among older citizens has confirmed the digital divide among seniors reported in previous research (Docampo Rama et al. 2001, Friemel 2016, Gatto \& Tak 2008, Loos 2012, Reisenwitz et al. 2007, Robinson et al. 2015, van Deursen \& Helsper 2015). The analysis has contributed to this understanding by showing the impact of different socio-demographic and social factors at different times throughout the diffusion process thus far. It is evident that patterns change with the development of the diffusion and 
applications studied. To understand how older citizens embrace technologies that could ease their lives in several aspects therefore means continuous measures of subgroups of seniors and of different specific applications in times series perspectives. Acceptance is never straightforward, no matter how essential the technology is believed to be, and 'the development of media technologies is an ongoing process, not an event' (Meikle \& Young 2012:33).

The digital gap due to age does seem to be closing, but at a very slow pace. And while Internet use is increasing among seniors, it is evident that older adults go through a similar process for specific and new digital applications. If the gap is left to close merely through Internet users' ageing, it will be several more years before just one out of two $80+$ is online, and the gap will most likely remain when adding new applications to the online everyday life. Considering the development of the Internet over the past 20 years and its ever-growing relevance for virtually every aspect of societal life, just allowing this to run its course does not seem to be a viable option for digital inequality initiatives.

The impact of social context emphasised in previous research (Davis 1989, Haddon 2000, Gatto \& Tak 2008, Friemel 2016) does not hold any strong explanatory value in the presented study. When controlling for other factors, the social effects turn out to be minor. Although still significant, it is evident when analysing survey data that socio-demographic and socio-economic factors constitute drivers in the Internet uptake process, and that internal motivations seem to override external ones.

Over a time period of about 15 years, the contributions of different factors to explain Internet use among elderly have somewhat changed. Sex differences have diminished, which means that the Internet generally has become more equal among elderly. The impact of education is, however, still strong which points to other inequalities still remaining. Although the age and education gaps are slowly decreasing, they are still significantly evident in 2015. Altogether, patterns seem to be slowly changing over time, in favour of life experiences both in work environments and in socialising with friends and family.

The present study has not taken any aspect of offline activity into consideration. It is reasonable to assume that offline activities do influence what happens online. Older people with little or no contact with their bank will, for instance, most likely not engage in online banking. On the other hand, a feasible digital application might be the spark leading to online activity. Future research should include different aspects of offline activities to reveal how interests and needs could be transferred from offline to online activities (c.f. Venkatesh et al. 2012).

It is evident that digital equality goes beyond mere access to Internet technology. The so-called usage gap (van Deursen \& van Dijk 2014) is clearly visible in the present analysis. Since digital uses and activities increasingly interfere with most spheres of daily life, not being online affects you in different ways. According to the findings, two out of three in the age group of 80-85 years are not taking any part in digital applications. Whether this is a problem to the individuals or not is an empirical question needed to be further emphasised in future studies. It is likely, however, that an increasingly digitised society might suffer from not having all citizens included in digital activities and involvement. 


\section{References}

Boulton-Lewis, Gillian M.; Buys, Laurie; Lovie-Kitchin, Jan; Barnett, Karen \& Davis, L. Nikki (2007). Aging, Learning, and Computer Technology in Australia. Educational Gerontology, 33(3): 253-270.

Bouwman, Harry \& Van Der Duin, Patrick (2007). Futures Research, Communication and the Use of Information and Communication Technology in Households in 2010: A Reassessment. New Media \& Society, 9(3): 379-399.

Brügger, Niels (2013). Web Histography and Internet Studies: Challenges and Perspectives. New Media \& Society, 15(5): 752-764.

Carpenter, Brian D. \& Buday, Sarah (2007). Computer Use among Older Adults in a Naturally Occurring Retirement Community. Computers in Human Behavior, 23(6): 3012-3024.

Davis, Fred (1989). Perceived Usefulness, Perceived Ease of Use, and User Acceptance of Information Technology. MIS Quarterly, 13(3): 319-340.

Davis, Richard (2005). Politics Online: Blogs, Chatrooms and Discussion Groups in American Democracy. New York and London: Routledge.

Dickinson, Anna; Arnott, John \& Prior, Suzanne (2007). Methods for Human-Computer Interaction Research with Older People. Behaviour \& Information Technology, 26(4): 343-352.

Dickinson, Anna \& Gregor, Peter (2006). Computer Use has no Demonstrated Impact on the Well-Being of Older Adults. International Journal of Human-Computer Studies, 64(8): 744-753.

Docampo Rama, Mili; de Ridder, Huib \& Bouma, Herman (2001). Technology Generation and Age in Using Layered User Interfaces. Gerontechjournal.net, 1(1): 25-40.

Fisch, Martin \& Christoph Gscheidle (2008). Mitmachnetz Web 2.0: Rege Beteiligung nur in Communitys. Media Perspektiven, 7: 356-364.

Friemel, Thomas N. (2016). The Digital Divide has Grown Old: Determinants of a Digital Divide among Seniors. New Media \& Society, 18(2): 313-331.

Gatto, Susan L \& Tak, Sunghee H. (2008). Computer, Internet, and E-mail Use among Older Adults: Benefits and Barriers. Education Gerontology, 34(9): 800-811.

Gersch, Beate (1998). Gender at the Crossroads: The Internet as a Cultural Text. Journal of Communication Inquiry, 22(3): 306-321.

Haddon, Leslie (2000). Social Exclusion and Information and Communication Technologies: Lessons from Studies of Single Parents and the Young Elderly. New Media \& Society, 2(4): 387-406.

Haddon, Leslie (2006). The Contribution of Domestication Research to In-Home Computing and Media Consumption. The Information Society: An International Journal, 22(4): 195-203.

Hargittai, Eszter (2008). Whose Space? Differences Among Users and Non-users of Social Network Sites. Journal of Computer-Mediated Communication, 13(1): 276-297.

Hargittai, Eszter \& Gina Malejko (2008). The Participation Divide: Content Creation and Sharing in the Digital Age. Information, Communication \& Society, 11(2): 239-256.

Helsper, Ellen (2010). Gendered Internet Use across Generations and Life Stages. Communication Research, 37(3): 352-374.

Internet World Stats (n.d.) Internet World Stats. URL www.internetworldstats.com. (accessed 2017-01-11).

Lenhart, Amanda; Madden, Mary; Macgill, Alexandra \& Aaron Smith (2007). Teens and Social Media. Pew Internet \& American Life Project. URL www.pewinternet.org/pdfs/PIP Teens_Social_Media_Final. pdf (accessed 2009-11-24).

Loos, Eugène (2012). Senior Citizens: Digital Immigrants in their Own Country? Observatorio (OBS), 6(1): $1-23$.

Mannheim, Karl (1952). The problem with generations, pp. 276-320 in Kecskemeti, Paul (ed.) Essays on the Sociology of Knowledge. London: Routledge \& Kegan Paul.

Meikle, Graham \& Young, Sherman (2012). Media Convergence. Networked digital media in everyday life. Basingstoke, NY: Palgrave Macmillan.

Obi, Toshio; Ishmatova, Diana \& Iwasaki, Naoko (2013). Promoting ICT Innovations for the Ageing Population in Japan. International Journal of Medical Informatics, 82: e47-e62.

Rains, Stephen A. (2008). Health at High Speed. Broadband Internet Access, Health Communication, and the Digital Divide. Communication Research, 35(3): 283-297.

Reisenwitz, Tim; Iyer, Rajesh; Kuhlmeier, David B. \& Eastman, Jacqueline K. (2007). The Elderly's Internet Usage: an Updated Look. Journal of Consumer Marketing, 24(7): 406-418.

Robinson, Laura; Cotton, Shelia R; Ono, Hiroshe; Quan-Haase, Anabel; Mesch, Gustavo; Chen, Wenhong; Schulz, Jeremy; Hale, Timothy M. \& Stern, Michael J. (2015). Digital Inequalities and Why they Matter. Information, Communication \& Society, 18(5): 569-582.

Rogers, Everett M. (2003). Diffusion of Innovations. New York: The Free Press.

Turkle, Sherry (1995). Life on the Screen: Identity in the Age of the Internet. New York: Simon and Schuster. 
van Deursen, Alexander JAM \& Helsper, Ellen J. (2015). A Nuanced Understanding of Internet Use and Nonuse Among Elderly. European Journal of Communication, 30(2): 171-187.

van Deursen, Alexander \& van Dijk, Jan (2011). Internet Skills and the Digital Divide. New Media \& Society, 13(6): 893-911.

van Deursen, Alexander \& van Dijk, Jan (2014). The Digital Divide Shifts to Differences in Usage. New Media \& Society, 16(3): 507-526.

Venkatesh, Viswanath; Thong, James Y. L. \& Xu, Xin (2012). Consumer Acceptance and Use of Information Technology: extending the Unified Theory of Acceptance and Use of Technology. MIS Quarterly, 36(1): 157-178.

Verkasalo, Hannu; López-Nicolás, Carolina; Molina-Castillo, Francisco H. \& Bouwman, Harry (2010). Analysis of Users and Non-users of Smartphone Applications. Telematics and Informatics, 27(3): 242-255.

Vernersdotter, Frida (2016). Den nationella SOM-undersökningen 2015, pp. 433-459 [The National SOM Survey 2015] in Ohlsson, Jonas; Oscarsson, Henrik \& Solevid, Maria (eds.) Ekvilibrium [Equilibrium]. Gothenburg: The SOM Institute, University of Gothenburg.

Victor, Christina; Westerhof, Gerben J. \& Bond, John (2007). Researching Ageing, pp. 85-112 in Bond, John; Peace, Sheila; Dittmann-Kohli, Freya \& Westerhof, Gerben (eds.) Ageing in Society. London, Thousand Oaks CA, New Delhi and Singapore: Sage Publications Ltd. Third edition.

Winston, Brian (1998). Media Technology and Society. A History: From the Telegraph to the Internet. London and New York: Routledge. 